\title{
Clenbuterol plasma concentrations after therapeutic administration in fit Standardbred horses: threshold recommendations
}

\author{
K.H. McKeever ${ }^{1 *}$, H.C. Manso Filho ${ }^{2}$, E.M. Rankins ${ }^{1}$, C.S. Duchamp ${ }^{1}$, Y. Salah ${ }^{1}$, C.K. Fenger ${ }^{3}$, W.C. Duer ${ }^{4}$, K. Malinowski ${ }^{1}$ and G.A. Maylin ${ }^{5}$ \\ 'Equine Science Center, Department of Animal Science, Rutgers - The State University of New Jersey, 84 Lipman Drive, New Brunswick, NJ \\ 08901, USA; ${ }^{2}$ Federal Rural University of Pernambuco, Rua Dom Manuel de Medeiro, 52171-900 Recife, PE, Brazil; ${ }^{3}$ Equine Integrated Medicine, \\ PLC, 4904 Ironworks Rd., Georgetown, KY 40324, USA; “ Duer Forensic Toxicology LLC., 1621 Gulf Blvd \#102, Clearwater, FL 33767-2928, USA; \\ ${ }^{5}$ New York Drug Testing and Research Program, Morrisville State College, 777 Warren Rd, Ithaca, NY 14853, USA; mckeever@sebs.rutgers.edu
}

Received: 8 September 2020 / Accepted: 29 September 2020

(c) 2021 Wageningen Academic Publishers

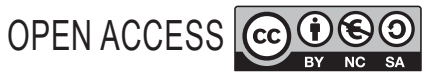

RESEARCH ARTICLE

\begin{abstract}
Clenbuterol, $(R S)$-1-(4-amino-3,5-dichlorophenyl)-2-(tert-butylamino)ethan-1-ol, as Ventipulmin is an FDA approved $\beta_{2}$ agonist medication for the management of airway obstruction in horses. Administration above the FDA approved doses for clenbuterol produces repartitioning effects, which have led to restrictions on its use in human athletics and Quarter Horse and Thoroughbred racing. Clenbuterol, however has long been used therapeutically at FDA approved doses in Harness racing. The goal of this study was to identify a withdrawal time guideline for its use at FDA approvsed dose levels in Harness racing, where horses may start at seven-day intervals. Eight healthy, moderately fit Standardbred horses (4 mares, 4 geldings, weight $491 \pm 40 \mathrm{~kg}$, age $13 \pm 2$ years) were administered 0.8 $\mu \mathrm{g} / \mathrm{kg}$ of clenbuterol as Ventipulmin syrup twice daily (BID) for three days. Blood samples were collected prior to dosing and at 1, 24, 48 and $96 \mathrm{~h}$ post administration. Clenbuterol was quantified in all samples using the New York Drug Testing and Research Laboratory ISO-17025 Racing and Medication Testing Consortium (RMTC) accredited quantitative procedure. The lower limit of quantitation of the method was $1.0 \mathrm{pg} / \mathrm{ml}$, and three data points at 96 $\mathrm{h}$ post administration were censored. One horse developed diarrhoea and data from this horse was excluded from the overall analysis. Plasma regulatory thresholds were calculated using the 95/95 tolerance method and Gauss Camp Meidell at $P=0.05$ and $P=0.001$. Horses were also evaluated for effects of clenbuterol on body composition using body mass and ultrasound measurements of rump fat thickness. There were no effects $(P>0.05)$ of clenbuterol on any of the measures including fat mass and fat free mass and thus no repartitioning effect was observed. The pharmacokinetic data and the $96 \mathrm{~h}$ data set support the therapeutic use of clenbuterol in Harness horses at the FDA approved $0.8 \mu \mathrm{g} / \mathrm{kg}$ BID dose for three days and suggest a $41 \mathrm{pg} / \mathrm{ml}$ regulatory threshold for a $96 \mathrm{~h}$ withdrawal time with a $P=0.001$ probability of randomly exceeding this regulatory threshold.
\end{abstract}

Keywords: horse, clenbuterol, racing, regulatory thresholds, Standardbred

\section{Introduction}

Inflammatory airway disease (IAD) is a widespread condition in horses resulting in impaired gas exchange and interference with optimal performance. This respiratory condition can affect as many as $80 \%$ of all 2 -year-old racehorses, 14\% of racing horses of all age groups (Wood et al., 2005), and is the second most common cause of lost training days in racehorses (Wilsher et al., 2006). Stabled racehorses are also subjected to high concentrations of fine particulate matter that can reach the lower airways, contributing to the incidence of IAD (Millerick-May et al., 2011).

Clenbuterol (Figure 1) is an FDA approved oral $\beta_{2}$ agonist (Ventipulmin ${ }^{\circledR}$ ) used for the management of IAD and airway obstruction in horses (Couëtil et al., 2016). Clenbuterol is unusual in that its phenolic chlorines increase the oral bioavailability and slows its metabolism as compared to other $\beta_{2}$-adrenoceptor agonist medications. These 
<smiles>CC(C)(C)NCC(O)c1cc(Cl)c(N)c(Cl)c1</smiles>

Figure 1. Clenbuterol, (RS)-1-(4-amino-3,5-dichlorophenyl)2-(tert-butylamino)ethan-1-ol, as $\mathrm{C}_{12} \mathrm{H}_{18} \mathrm{Cl}_{2} \mathrm{~N}_{2} \mathrm{O}$, molar mass $277.19 \mathrm{~g} / \mathrm{mol}$.

characteristics make clenbuterol a therapeutically useful, orally active, $\beta_{2}$ agonist bronchodilator (Collett et al., 1983; Harkins et al., 2000). Clenbuterol decreases pulmonary resistance by relaxing bronchial smooth muscle, facilitating airflow and alleviating the clinical signs and outcomes of airway obstruction. Clenbuterol administration acts to mitigate bronchial spasms, thin mucous secretions (Sasse and Hajer, 1977) and improve mucociliary clearance of particulates by increasing ciliary beat frequency (Turgut and Sasse, 1989).

Like other $\beta_{2}$-agonists, clenbuterol has been shown to induce repartitioning effects, wherein the crosssectional area of muscle is increased following prolonged administration of clenbuterol, starting in the middle of the recommended dose range $(2.5 \mu \mathrm{g} / \mathrm{kg}$, twice daily (BID), Kearns et al., 2001), and the percent body fat is also decreased without a measurable effect on fat free mass at the lower end of the dose range $(0.8 \mu \mathrm{g} / \mathrm{kg}$, Nolen-Walston et al., 2015). Clenbuterol is therefore classified as a Class 3 , penalty class $\mathrm{B}$ substance by the Association of Racing Commissioners International (ARCI, 2020). Similarly, this repartitioning effect occurs in humans on high doses of clenbuterol. This effect has led the World Anti-Doping Agency (WADA) to ban clenbuterol in human athletics, using a threshold of $5 \mathrm{ng} / \mathrm{ml}$ in urine as evidence of misuse. Detections below $5 \mathrm{ng} / \mathrm{ml}$ are investigated for a food related origin or other incidental environmental source of the identification (USADA, 2019).

These effects of clenbuterol on the structure and function of skeletal muscle do not, however, translate into improved equine performance in aerobic competition. FDA approved dose administrations $(2.4 \mu \mathrm{g} / \mathrm{kg})$ of clenbuterol at for 8 weeks resulted in a $6 \%$ decrease in maximal oxygen consumption $\left(\mathrm{VO}_{2 \max }\right), 21 \%$ decrease in time to fatigue, and impaired cardiovascular recovery after exercise (Kearns and McKeever, 2002). Despite these research findings, however, clenbuterol has reportedly been widely used for performance enhancing effects in Quarter Horses (Anonymous, 2015), and such inappropriate use has at times resulted in the administration of large doses of compounded clenbuterol products, resulting in severe injury and death (Thompson et al., 2011).

Overall, the negative effects of clenbuterol on aerobic athletic performance limit its inappropriate prolonged or high dose use in Harness racing, which requires aerobic fitness. However, in order to permit the therapeutically appropriate use of clenbuterol in the prevention or treatment of respiratory disease in Standardbred athletes, and to prevent inappropriate use, regulatory thresholds to guide and govern its approved therapeutic use in Standardbred racing must be identified.

Regulations governing the use of clenbuterol in horse racing vary widely. The current ARCI model rules suggest a 14-day withdrawal with a $140 \mathrm{pg} / \mathrm{ml}$ threshold in urine, while no detectable clenbuterol in either blood or urine is permitted in Quarter Horses in most jurisdictions at this time. The lack of muscle partitioning effects when used for $<5$ days (Nolan-Watson et al., 2015), and the negative performance (ergolytic) effects when used chronically (Kearns and McKeever, 2002) indicates that a conservative three-day treatment with the FDA approved conservative dose regimen of $0.8 \mu \mathrm{g} / \mathrm{kg}$ BID would permit the therapeutic use of clenbuterol in Standardbred horses having IAD without either ergogenic or ergolytic effects. This study was conducted to identify a plasma clenbuterol threshold at $96 \mathrm{~h}$ in fit Standardbred horses after three days of such a treatment protocol, and to identify any potential repartitioning effects.

\section{Materials and methods}

\section{Study facilities and animals}

Eight healthy, moderately fit Standardbred horses (4 mares, 4 geldings, weight $491 \pm 40 \mathrm{~kg}$ (range $427-558 \mathrm{~kg}$ ), age $13 \pm 2$ years) were used in this study. Prior to the study, the horses were determined to be healthy by physical examination. Each horse was acclimated to the study procedures, housing in stalls and the feeding regime for the duration of the study. Horses were fed a grass hay ration twice a day. The ration met the 2007 National Research Council recommendations for maintenance. Hay samples were analysed by a commercial laboratory (DairyOne Forage Laboratory, Ithaca, NY, USA. On an as-fed basis, hay provided $\sim 0.95 \mathrm{Mcal} / \mathrm{kg}$ each day. Additionally, the horses had ad libitum access to water and a salt/mineral block. The study was approved by the Rutgers University Animal Care and Use Committee.

\section{Experimental design}

The study was divided into three periods (Table 1). There was a six-day pre-experiment control period where each horse was weighed every day at 15:00 PM on each of the six 
Table 1. General experimental design and timeline.

\begin{tabular}{|c|c|c|c|c|c|c|}
\hline & \multicolumn{6}{|c|}{ Control period - no drug } \\
\hline & Day 1 (Thu) & Day 2 (Fri) & Day 3 (Sat) & Day 4 (Sun) & Day 5 (Mon) & Day 6 (Tue) \\
\hline \multicolumn{7}{|l|}{ Dosing } \\
\hline Weight & 13:00 PM & 14:00 PM & 15:00 PM & 15:00 PM & 15:00 PM & 15:00 PM \\
\hline Ultrasound & & & & & 15:00 PM & 15:00 PM \\
\hline \multirow[t]{3}{*}{ Blood } & & & & & 15:00 PM & 15:00 PM \\
\hline & \multicolumn{6}{|c|}{ Drug administration } \\
\hline & \multicolumn{2}{|l|}{ Day 7 (Wed) } & \multicolumn{2}{|l|}{ Day 8 (Thu) } & \multicolumn{2}{|l|}{ Day 9 (Fri) } \\
\hline Dosing & \multicolumn{2}{|c|}{ 8:00 AM \& 15:00 PM } & \multicolumn{2}{|c|}{ 8:00 AM \& 15:00 PM } & \multicolumn{2}{|c|}{ 8:00 AM \& 15:00 PM } \\
\hline Weight & \multicolumn{2}{|c|}{$\sim 15: 00 \mathrm{PM}$} & \multicolumn{2}{|c|}{$\sim 15: 00 \mathrm{PM}$} & \multicolumn{2}{|c|}{$\sim 16: 00 \mathrm{PM}$} \\
\hline Ultrasound & & & & & 16:00 PM & \\
\hline \multirow[t]{3}{*}{ Blood } & & & & & 16:00 PM & \\
\hline & \multicolumn{4}{|c|}{ Withholding period } & & \\
\hline & Day 10 (Sat) & Day 11 (Sun) & Day 12 (Mon) & Day 13 (Tue) & & \\
\hline \multicolumn{7}{|l|}{ Dosing } \\
\hline Weight & 15:00 PM & $\sim 15: 00$ PM & 15:00 PM & $\sim 15: 00$ PM & & \\
\hline Ultrasound & & & & $\sim 15: 00$ PM & & \\
\hline Blood & 15:00 PM & $\sim 15: 00$ PM & & 15:00 PM & & \\
\hline
\end{tabular}

days prior to clenbuterol administration so as to document that they were in a stable plane of body weight. Preadministration control body composition measurements and blood sampling were also performed during this period at 15:00 $\mathrm{PM}$ at -48 and $-24 \mathrm{~h}$ prior to the first administration of clenbuterol. The dosing period followed with the administration of $0.8 \mu \mathrm{g} / \mathrm{kg}$ oral clenbuterol (Ventipulmin ${ }^{\circledR}$, Boehringer-Ingelheim, St. Joseph, MO, USA) twice daily at 8:00 AM and 15:00 PM for three days using the dosing syringe provided by the manufacturer. Blood samples were collected at -48 and $-24 \mathrm{~h}$ prior to clenbuterol administration, and at $+1,+24,+48$ and $+96 \mathrm{~h}$ following the last dose of clenbuterol administration. Jugular blood samples $(20 \mathrm{ml})$ were obtained via venipuncture and placed into tubes containing lithium heparin (Vacutainer, Becton Dickinson, Inc, Franklin Lakes, NJ, USA). The tubes were immediately placed on ice until they were centrifuged at $2,000 \times g$ for $5 \mathrm{~min}$ and plasma was stored at $-80{ }^{\circ} \mathrm{C}$ until shipped on ice to the New York Drug Testing and Research Program, for measurement of clenbuterol concentration.

Rump fat thickness was measured by B-mode ultrasonography twice before the start of the study at -48 and -24 $\mathrm{h}$, and +1 and $+96 \mathrm{~h}$ following the last dose of clenbuterol. The average of 4 measurements ( 2 left and 2 right) were used to calculate percent body fat (\%fat) as previously described (Kane et al., 1987; Kearns et al. 2001). Briefly, a site $5 \mathrm{~cm}$ lateral from midline at the center of the pelvis was identified and clipped to facilitate identification of the same site. The region was scanned, and the position of maximal fat thickness was used for measurement. Percent fat was estimated from the equations of Kane et al. (1987): where \%fat $=2.47+5.47$ (rump fat thickness in $\mathrm{cm}$ ). Fat mass was calculated by multiplying \%fat and total body mass. Fat-free mass (FFM) was derived by subtracting fat mass from total body mass.

\section{Analytical methods}

The analytical procedure followed was the ISO 17025/ RMTC accredited quantitative analytical procedure for clenbuterol in place in the New York Drug Testing and Research Laboratory. The analytical reference standard for clenbuterol was purchased from Sigma Aldrich (St. Louis, MO, USA) and d9-clenbuterol from Toronto Research Chemicals (North York, Canada). Stock solutions of clenbuterol and d9-clenbuterol were prepared at $1 \mathrm{mg} / \mathrm{ml}$ in methanol. Acetonitrile and methanol were purchased from EMD Millipore (St. Louis, MO, USA), ammonium formate was purchased from Fisher Scientific (Lenexa, 
KS, USA), n-butyl chloride was purchased from SigmaAldrich, and sodium carbonate was purchased from VWR (Monroeville, PA, USA). Deionised water was filtered onsite to the specification of $18.2 \mathrm{meg} \Omega$. Ethanol was purchased from Pharmco-Aaper (Brookfield, CT, USA). All reagents were of HPLC grade or better.

Working clenbuterol solutions were prepared by dilution of the $1 \mathrm{mg} / \mathrm{ml}$ stock solution with methanol to a concentration of $10 \mathrm{pg} / \mu \mathrm{l}$. Plasma calibrators in concentrations of 10 , 50,100 , and $500 \mathrm{pg} / \mathrm{ml}$ and a quality control sample at a concentration of $100 \mathrm{pg} / \mathrm{ml}$ was prepared by the addition of the working standard solution to drug-free plasma harvested from experimental horses known to be drugfree. Calibration curves and negative control samples were prepared fresh for each quantitative assay.

The $1.0 \mathrm{ml}$ aliquots of samples were prepared alongside the calibration curve and negative control samples. Internal standard was added to each tube. Samples were mixed by vortex, and $2 \mathrm{ml}$ of saturated sodium carbonate solution and $5 \mathrm{ml}$ of $\mathrm{n}$-Butyl Chloride ( $\mathrm{nBC}$ ) were added. Samples were mixed by rotation for $10 \mathrm{~min}$, centrifuged at 2,400×g for $5 \mathrm{~min}$, the emulsion broken, and centrifuged again at $2,400 \times g$ for 5 more min. The top $\mathrm{nBC}$ layer was removed and dried under nitrogen. Samples were dissolved in $50 \mu \mathrm{l}$ of equal parts acetonitrile, methanol, and deionised water. $5.0 \mu \mathrm{l}$ was injected into the LC-MS/MS system (Agilent Technologies, Santa Clara, CA, USA) coupled with a U/ HPLC chromatography system (Agilent Technologies).

The concentration of clenbuterol was measured in plasma by LC-MS/MS using positive electrospray ionisation with Agilent Jet Stream technology. Chromatography employed a Phemomenex Gemini-NX C18 column with a length of $100 \mathrm{~mm}$ and a pore size of $3.0 \mu \mathrm{m}$ (Phenomenex, Torrance, CA, USA). The beginning mobile phase composition was 90\% acetonitrile:MeOH:0.1\% formic acid (20:20:60, v/v/v) and 10\% acetonitrile:MeOH:Di- $\mathrm{H}_{2} \mathrm{O}$ (45:45:10, v/v/v). The initial acetonitrile:MeOH:0.1\% formic acid concentration was held at $90 \%$ for $0.5 \mathrm{~min}$, dropped to $5 \%$ until $1 \mathrm{~min}$, and held at that concentration until $4.5 \mathrm{~min}$ at which the mobile phase composition was reset to the initial settings.

Detection and quantification were conducted using selective reaction monitoring (SRM) of initial precursor ion for clenbuterol (mass-to-charge ratio $277 \mathrm{~m} / \mathrm{z}$ ) and the internal standard $(286 \mathrm{~m} / z)$. The response for the product ions for clenbuterol $(m / z 132,168,203)$ and the internal standard $(\mathrm{m} / \mathrm{z} 204)$ were plotted and peaks at the proper retention time integrated using MassHunter software (Agilent). MassHunter software was used to generate calibration curves and quantitate clenbuterol in all samples by linear regression analysis.
The validation of the method employed for the analysis of clenbuterol contained a calibration curve performed encompassing 10, 50, 100, and $500 \mathrm{pg} / \mathrm{ml}$ clenbuterol. The response was linear and gave correlation coefficients $\left(R^{2}\right)$ of 0.99 or better. Quality control samples replicates were performed $(n=7)$. The inter-day accuracy was $7.9 \%$ for 20 $\mathrm{pg} / \mathrm{ml}$ clenbuterol. The intra-day accuracy was $7.9 \%$ for 20 $\mathrm{pg} / \mathrm{ml}$ clenbuterol. The technique was optimised to provide a limit of quantitation (LOQ) of $0.55 \mathrm{pg} / \mathrm{ml}$. The limit of detection (LOD) was $0.16 \mathrm{pg} / \mathrm{ml}$.

\section{Data analysis}

The 24, 48 and $96 \mathrm{~h}$ post administration plasma clenbuterol concentrations were analysed for percentage of censored (below the lower LOQ) data, summary statistics obtained using Robust Regression on Order and General Linear Model statistical methods (Helsel, 2012). The datasets were first analysed for percent censored data, then normality tests (Shapiro-Wilk, Anderson-Darling and Lillefors) were performed on uncensored (above LOQ) data (using MS Excel; Microsoft, Redmond, WA, USA) in order to determine the most appropriate statistical analysis for threshold determination. Summary statistics for each data subgroup were obtained for each group using RROS (Helsel, 2012) in R-programming language and bootstrap analyses with 100,000 resamplings (XLSTAT ${ }^{\oplus}$; ADDinsoft 2016, https://www.xlstat.com/en/ as an Excel ${ }^{\circ}$ for Mac 2011, Microsoft add-in). Bootstrap with resampling was performed to estimate population summary statistics. Thresholds for each dataset were determined using two different methods; (95/95) tolerance interval (Owen, 1968) and Gauss-Camp-Meidell (Savage, 1961) (GCM), as previously described (Machin et al., 2019). The 95/95 tolerance is calculated by:

$\ln \left(\mathrm{x}_{\mathrm{tol}}\right)=\mathrm{m}+\mathrm{ks}_{\mathrm{x}}$

Where $\ln \left(x_{\text {tol }}\right)$ is the naperian logarithm of the $95 / 95$ tolerance threshold, $\mathrm{m}$ is the mean and $\mathrm{s}_{\mathrm{x}}$ is the standard deviation of the naperian logarithm of the sample concentrations. The $\mathrm{k}$ value is a tolerance limit factor equivalent to a z-score corrected for sample size (Owen, 1968). The GCM is a probability inequality that provides bounds for the probability that the plasma concentration will fall within a given $\mathrm{p}$-value, and requires only a unimodal distribution (Savage, 1961). Body composition data was analysed using ANOVA for repeated measures with a level of significance set at $P<0.05$ (Sigmastat 4.0; Systat, San Jose, CA, USA). 


\section{Results}

Validation of the ISO 17025/RMTC accredited quantitative analytical procedure for clenbuterol included a calibration curve of 10, 50, and $100 \mathrm{pg} / \mathrm{ml}$ clenbuterol. The analyte response was linear and gave correlation coefficients $\left(\mathrm{R}^{2}\right)$ of 0.99 or better. Inter-day precision (\% relative standard deviation) at $20 \mathrm{pg} / \mathrm{ml}$ was $3.8 \%$, intra-day precision (\% relative standard deviation) was $3.8 \%$. Inter-day accuracy at $20 \mathrm{pg} / \mathrm{ml}$ (\% nominal concentration) was $7.9 \%$. Intra-day accuracy was $7.9 \%$ at $20 \mathrm{pg} / \mathrm{ml}$. The LOD was $0.16 \mathrm{pg} / \mathrm{ml}$, and the lower LOQ was $0.55 \mathrm{pg} / \mathrm{ml}$.

Eight horses were initially studied, but one horse was deemed to have a significant disturbance in her gastrointestinal tract that caused an increase in transit time and very loose stool and thus, her data were excluded from the analyses. The data are reported for the purpose of providing guidance to horsemen and veterinarians where a horse may have gastrointestinal disease. Three censored data points occurred in the $96 \mathrm{~h}$ plasma clenbuterol data set. The horse that developed mild diarrhoea was excluded from the pharmacokinetic and statistical analysis but the data points are presented as the dotted line in Figure 2.

The terminal plasma half-life values calculated from 48$96 \mathrm{~h}$ pharmacokinetic parameters for each of the 7 horses are presented in Table 2 . The slope $(\lambda)$, rate constant $(\mathrm{k})$

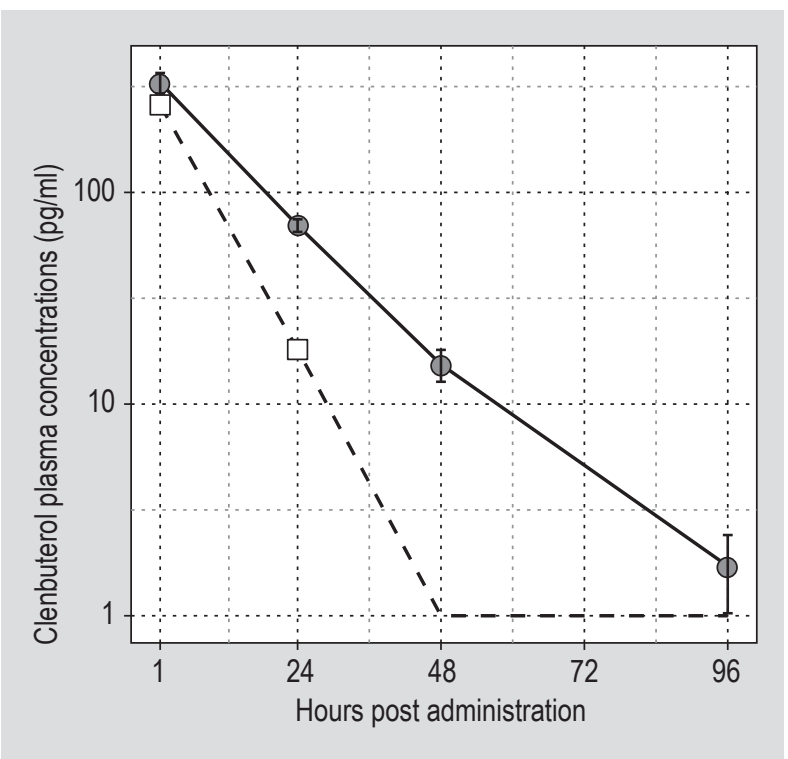

Figure 2. Semi-logarithmic transformation of the data plotting the mean ( \pm standard deviation) plasma concentrations of clenbuterol at $1,24,48$, and $96 \mathrm{~h}$ following the administration of $0.8 \mathrm{ug} / \mathrm{kg}$ BID for three days. The plot with a broken line represents data from the horse with very loose, watery faeces. The solid black line represents the data for the remaining 7 horses. and plasma elimination half-life $\left(t_{1 / 2}\right)$ were calculated for clenbuterol plasma concentration data for each individual horse (Jambhekar and Breen, 2012). Pharmacokinetic parameters for clenbuterol are reported as means \pm standard deviation, and range. For each time point, the number of censored data points and calculated thresholds are presented in Table 3. The semi-log transformation of the average clenbuterol concentration vs time curves are shown in Figure 2. Summary statistics were determined for the 96 $\mathrm{h}$ time point using Robust Regression on Order to impute the values of the censored data points, as shown in Table 4. Indices of body composition calculated from the measured rump fat thickness and body mass were unaffected $(P>0.05)$ by the administration of $0.8 \mu \mathrm{g} / \mathrm{ml}$ clenbuterol twice daily for 3 days (Table 5).

Table 2. Pharmacokinetic parameters of clenbuterol following administration of $0.8 \mu \mathrm{g} / \mathrm{kg}$ body weight. ${ }^{1,2}$

\begin{tabular}{|c|c|c|}
\hline $\begin{array}{l}\text { Pharmacokinetic } \\
\text { parameters }\end{array}$ & $\begin{array}{l}\text { Mean } \pm \text { standard } \\
\text { deviation }\end{array}$ & Range \\
\hline$\lambda(/ \mathrm{h})$ & $0.023 \pm 0.002$ & $0.020-0.027$ \\
\hline k & $0.054 \pm 0.006$ & $0.047-0.062$ \\
\hline$t_{1 / 2}$ & $12.9 \pm 1.3$ & $11.1-14.7$ \\
\hline $\mathrm{AUC}_{0-\infty}(\mathrm{pg} / \mathrm{h} / \mathrm{ml})$ & $6,369 \pm 1,612$ & $4,351-8,840$ \\
\hline$\lambda_{\text {term }}(/ / \mathrm{h})$ & $0.019 \pm 0.0004$ & $0.013-0.023$ \\
\hline $\mathrm{k}_{\text {term }}$ & $0.04 \pm 0.01$ & $0.03-0.06$ \\
\hline$t_{1 / 2 \text { term }}(h)$ & $16.9 \pm 4.3$ & $12.1-22.8$ \\
\hline \multicolumn{3}{|c|}{$\begin{array}{l}{ }^{1} \text { Clenbuterol (Ventipulmin }{ }^{\circledR} \text { ) syrup orally twice (BID) daily for three days } \\
\text { to racing fit Standardbreds. Pharmacokinetic (PK) parameters determined } \\
\text { from all data evaluated as mono-exponential. Terminal PK parameters } \\
\text { determined from the } 48 \text { and } 96 \mathrm{~h} \text { data points. } \\
{ }^{2} \lambda=\text { slope, } \mathrm{k}=\text { rate constant, } \mathrm{t}_{1 / 2}=\text { half-life, } \lambda_{\text {term }}=\text { terminal slope, } \mathrm{k}_{\text {term }} \\
=\text { terminal rate constant, } \mathrm{t}_{1 / 2 \text { term }}=\text { terminal half-life; } \mathrm{AUC}=\text { area under } \\
\text { the curve. }\end{array}$} \\
\hline
\end{tabular}

Table 3. The number of censored data points, and clenbuterol threshold levels in $\mathrm{pg} / \mathrm{ml}$ as determined by $95 / 95$ tolerance, Gauss-Camp-Meidell (GCM) at $P=0.05$, corresponding to 1 in 20 risk of violating the threshold, and $P=0.001$, corresponding to 1 in 1000 risk of violating the threshold.

$\begin{array}{lrr} & 48 \mathrm{~h} & 96 \mathrm{~h} \\ \text { Number censored data points } & 0 & 3 \\ 95 / 95 \text { tolerance } & 58 & 25 \\ \operatorname{GCM}(P=0.05) & 33 & 9 \\ \operatorname{GCM}(P=0.001) & 112 & 41\end{array}$


Table 4. Summary statistics for plasma clenbuterol concentrations at time points of $24 \mathrm{~h}, 48 \mathrm{~h}$ and $96 \mathrm{~h}$ post administration of $0.8 \mu \mathrm{g} / \mathrm{kg}$ twice daily for 3 days.

\begin{tabular}{lccl} 
& \multicolumn{2}{c}{ Time after last clenbuterol administration } & \\
\cline { 2 - 4 } & $24 \mathrm{~h}$ & $\mathbf{4 8} \mathrm{h} \mathrm{h}^{\mathbf{1}}$ \\
Mean & & & 2.04 \\
Standard deviation & 69.85 & 15.39 & 1.49 \\
Median & 12.65 & 6.99 & 1.5 \\
Skewness & 68.46 & 13.3 & 0.64 \\
Kurtosis & 0.40 & 1.48 & 1.86 \\
\hline
\end{tabular}

${ }^{1}$ Summary statistics for $96 \mathrm{~h}$ includes data imputed by robust regression on order owing to 3 censored data points.

Table 5. Indices of body composition (mean \pm standard deviation).

\begin{tabular}{|c|c|c|c|c|}
\hline & $-24 \mathrm{~h}$ & $-48 \mathrm{~h}$ & $+1 \mathrm{~h}$ & $+96 \mathrm{~h}$ \\
\hline Rump fat thickness (cm) & $1.9 \pm 0.4$ & $2.0 \pm 0.3$ & $2.0 \pm 0.4$ & $1.9 \pm 0.3$ \\
\hline Percent body fat & $12.9 \pm 2.3$ & $13.2 \pm 1.8$ & $13.2 \pm 2.0$ & $13.1 \pm 1.7$ \\
\hline Body mass (kg) & $491 \pm 40$ & $488 \pm 37$ & $494 \pm 39$ & $495 \pm 41$ \\
\hline Fat mass (kg) & $64 \pm 13$ & $64 \pm 11$ & $65 \pm 11$ & $65 \pm 10$ \\
\hline Fat free mass $(\mathrm{kg})$ & $427 \pm 31$ & $423 \pm 32$ & $428 \pm 35$ & $431 \pm 37$ \\
\hline
\end{tabular}

\section{Discussion}

Clenbuterol is the only FDA approved medication indicated for the management of IAD and obstructive airway disease in horses (Couetil et al., 2016). Because IAD commonly affects racehorses in training, the use of clenbuterol is appropriate. However, because at higher doses it may also cause a transition from a slow twitch-oxidative to fast twitch-glycolytic muscle profile, it may impact anaerobic performance (Kearns and McKeever, 2002). Therefore, this study was performed to delineate the terminal elimination of clenbuterol after administration at the low end of the therapeutic dose range of $0.8 \mathrm{ug} / \mathrm{kg}$ dose BID to race-fit Standardbred horses for three days. The pharmacokinetics identified herein provide sufficient data with which to make threshold and withdrawal recommendations for this dose regimen.

This study focused on the terminal elimination phase because this is the region of concern when establishing thresholds for prescribed withdrawal times. If the terminal portion of the elimination curve is limited by either inability to collect sufficient samples, or lack of sensitivity of the testing methodology, the true slope of the terminal elimination curve cannot be determined. When the data presented are evaluated as mono-exponential, our pharmacokinetic parameters closely follow those of previous investigators, with our observed clenbuterol half- life of $12.9 \mathrm{~h}$ mirroring the findings of Soma et al. (2004) at 12.9 h, Knych et al. (2016) at 10.4 h, and Lehner et al. (2001) at $7 \mathrm{~h}$. However, the LOQ of the methods used in previous studies was $13 \mathrm{pg} / \mathrm{ml}$ (Lehner et al., 2001; Soma et al., 2004) and $10 \mathrm{pg} / \mathrm{ml}$ (Knych et al., 2016), whereas the LOQ in this present study was $0.55 \mathrm{pg} / \mathrm{ml}$ permitting more accurate and definitive determination of the terminal elimination of clenbuterol. When just the 48 to $96 \mathrm{~h}$ data are evaluated, the terminal half-life of $16.9 \mathrm{~h}$ is significantly longer than previously reported. This finding is not unexpected because of the highly sensitive analytical method employed in the current study.

Prolonged high dose treatment with clenbuterol has been shown to be detrimental to the equine athlete, because of ergolytic effects (Kearns and McKeever, 2002) and cardiotoxic effects (Sleeper et al., 2002). Further, it exerts a repartitioning effect, where the transformation from a slow twitch-oxidative to fast twitch-glycolytic muscle profile could impact anaerobic performance because of increased power (Kearns et al., 2001). This latter effect has resulted in the prohibition of clenbuterol, as well as other $\beta_{2}$ agonists, in human athletics, with its detection above $5 \mathrm{ng} / \mathrm{ml}$ in urine is considered evidence of misuse. Detections below $5 \mathrm{ng} / \mathrm{ml}$ are investigated for a food related origin or other incidental environmental source of the identification (Anonymous, 2015). Clenbuterol abuse in humans is predominantly found among body builders and 
for weight loss (Milano et al., 2018) as opposed to athletes competing in aerobic events.

The dosing regimen ( $0.8 \mu \mathrm{g} / \mathrm{kg}$ BID for 3 days $)$ employed in this study detected no repartitioning effects, as measured by FFM. Our findings are in agreement with previous studies, which found no effect on FFM at a dose of $2.4 \mu \mathrm{g} / \mathrm{kg}$ BID until 6 weeks of administration in trained Standardbreds (Kearns et al., 2001), and no effect on FFM in trained polo ponies at the same dose of $0.8 \mu \mathrm{g} / \mathrm{kg}$ BID for 3 weeks (Nolen-Walston et al., 2015). This finding confirms that a 3 -day course of clenbuterol at $0.8 \mu \mathrm{g} / \mathrm{kg}$ BID is unassociated with detectable repartitioning that could influence racing performance.

The horse with mild diarrhoea that was present before the dosing regimen was initiated received clenbuterol, but was not included in the pharmacokinetic model, because of the pre-existing condition. As shown in Figure 2, this horse either eliminated the drug more rapidly or possibly absorbed it less completely. Bioavailability was not evaluated in this study, but may range from 68.3 to $87.7 \%$ in healthy horses (Soma et al., 2004). It is likely that the diarrhoea in this horse contributed to either a more rapid digestive transit time or malabsorption, either of which would decrease the bioavailability of clenbuterol. Because of the diarrhoea and the atypical pharmacokinetics this horse was excluded from the data analysis, but the data points are for informational purposes.

Plasma threshold levels were calculated using the 95/95 tolerance method, and the GCM at $P=0.05$ and GCM at $P=0.001$. The $95 / 95$ tolerance methodology provides a $95 \%$ confidence that $95 \%$ of the values will fall below the calculated threshold, when the underlying data are normally distributed (Owen, 1968). A number of assumptions are made in the calculation of 95/95 tolerance, which have previously been discussed (Owen, 1968), as well as the drawbacks associated with the use of this statistical methodology where sample sizes are small (Machin et al., 2019). The GCM is a probability inequality that posits for unimodal distributions that no more than a certain fraction of values will exceed a specified distance from the mean (Savage, 1961).

The statistical methods employed for threshold determination in this study dataset require several assumptions. The RROS methodology of imputing values for censored data requires that the clenbuterol concentrations below the LOQ follow the same distribution as the measured concentrations. Therefore, the statistical moments calculated from those RROS estimates must be considered in light of these assumptions, where $42 \%$ of the data cannot be directly quantified.
Pharmacokinetics differ not only between Standardbreds and Thoroughbreds, but also between animals that are fit or sedentary (Khazaeinia et al., 2000). The relevant pharmacokinetic parameters from our study are similar to previous studies which evaluated sedentary horses (Lehner et al., 2001; Soma et al., 2004) and race fit Thoroughbreds (Knych et al., 2016), which suggests that fitness and breed characteristics do not influence clenbuterol metabolism in horses. However, because the previous studies lacked the more sensitive analytical methodology used in this study, no conclusions can be drawn about possible differences in the terminal pharmacokinetic parameters between breeds or levels of fitness.

In conclusion, these data show that a $41 \mathrm{pg} / \mathrm{ml}$ plasma threshold for clenbuterol is a practical threshold to regulate the use of a three-day BID $0.8 \mathrm{ug} / \mathrm{kg}$ administration protocol for clenbuterol in racing Standardbred horses, where the horse may be racing again $96 \mathrm{~h}$ after the last administration. Additionally, the data presented here show that this low dose three-day administration schedule was without effect on the fat free mass of these horses, consistent with the effects of this therapeutic administration schedule being limited to the respiratory system.

\section{Conflict of interest}

The authors declare no conflict of interest.

\section{References}

Anonymous, 2015. AQHA makes clenbuterol a banned substance. Quarter Horse News, 2 September 2015. Available at: https:// tinyurl.com/y42kdnes

Association of Racing Commissioners International (ARCI), 2020. Drug testing standards and practices program. Uniform classification guidelines for foreign substances and recommended penalties model rule. January 2020 (V.14.1). Available at: https://tinyurl. com/y4w6cyxh

Collett, L., Kamerling, S., Woods, W.E., Weckman, T., Nugent, T., DeQuick, D. and Tobin, T., 1983. Clearance times and behavioral effects of clenbuterol in the horse. In: Proceedings of the $5^{\text {th }}$ International Conference of Cont. Use Drugs Racehorses. Toronto, Canada, pp. 265-271.

Couëtil, L.L., Cardwell, J.M., Gerber, V., Lavoie, J.-P., Léguillette, R. and Richard, E.A., 2016, Inflammatory airway disease of horses - revised consensus statement. Journal of Veterinary Internal Medicine 30: 503-515. https://doi.org/10.1111/jvim.13824

Harkins, J.D., Robinson, N.E., Woods, W.E., Lehner, A.F., Smith, M.D., Gates, R.S., Fisher, M. and Tobin, T., 2000. Intratracheal clenbuterol in the horse: its pharmacological efficacy and analytical detection. Journal of Veterinary Pharmacology and Therapeutics 23: 251-260. Helsel, D.R., 2012. Statistics for censored environmental data using Minitab and R. Vol. 77. John Wiley and Sons, Hoboken, NJ, USA. 
Jambhekar, S.S. and Breen, P.J., 2012. Extravascular routes of drug administration. In: Foster, R.W. (ed.) Basic pharmacology, $2^{\text {nd }}$ edition. Butterworths, London, UK, pp. 105-126.

Kane, R.A., Fisher, M., Parrett, D. and Lawrence, L.M., 1987. Estimating fatness in horses. In: Proceedings of the $10^{\text {th }}$ Equine Nutrition and Physiology Symposium, Fort Collins, CO, USA, pp. 127-131.

Kearns, C.F. and McKeever, K.H., 2002. Clenbuterol diminishes aerobic performance in horses. Medicine and Science in Sports and Exercise 34: 1976-1985. https://doi.org/10.1249/01. MSS.0000038973.96796.1E.

Kearns, C.F., McKeever, K.H., Malinowski, K., Struck, M.B. and Abe, T., 2001. Chronic administration of therapeutic levels of clenbuterol acts as a repartitioning agent. Journal of Applied Physiology 91: 2064-2070. https://doi.org/10.1152/jappl.2001.91.5.2064.

Khazaeinia, T., Ramsey, A.A. and Tam, Y.K., 2000. The effects of exercise on the pharmacokinetics of drugs. Journal of Pharmaceutical Sciences 3: 292-302.

Knych, H.K., Harrison, L.M., Steinmetz, S.J., Chouicha, N. and Kass, P.H., 2016. Differential expression of skeletal muscle genes following administration of clenbuterol to exercised horses. BMC Genomics 17: 596. https://doi.org/10.1186/s12864-016-2945-2

Lehner, A.F., Harkins, J.D., Karpiesiuk, W., Woods, W.E., Robinson, N.E., Dirikolu, L., Fisher, M. and Tobin, T., 2001. Clenbuterol in the horse: confirmation and quantitation of serum clenbuterol by LC-MS-MS after oral and intratracheal administration. Journal of Analytical Toxicology 25: 280-287.

Machin, J., Duer, W., Maylin, G., Fenger, C., Wilson, D., Ivey, M., Berthold, B., Allison, S. and Tobin, T., 2019. Variability in plasma concentrations of methylprednisolone 6 days after intrasynovial injection of methylprednisolone acetate in racing horses: a field study. Equine Veterinary Journal 51: 343-348.

Milano, G., Chiappini, S., Mattioli, F., Martelli, A. and Schifano, F., 2018. $\beta-2$ agonists as misusing drugs? Assessment of both clenbuterol- and salbutamol-related European Medicines Agency (EMA) pharmacovigilance database reports. Basic and Clinical Pharmacology and Toxicology 123:182-187.

Millerick-May, M.L., Karmaus, W., Derksen, F.J., Berthold, B., Holcombe, S.J. and Robinson, N.E., 2011. Particle mapping in stables at an American Thoroughbred racetrack. Equine Veterinary Journal 43: 599-607.
Nolen-Walston, R.D., Moore, C.M., Barr, C.A., Tomlinson, J.E., Boston, R.C. and Soma, L.R., 2015. Effect of long-term oral administration of a low dosage of clenbuterol on body fat percentage in working and nonworking adult horses. American Journal of Veterinary Research 76: 460-466. https://doi.org/10.2460/ajvr.76.5.460

Owen, D.B., 1968. Survey of properties and applications of the noncentral t-distribution. Technometrics 10: 445-478.

Sasse, H.H. and Hajer, R., 1977. Veterinary and clinical experience of the use of a beta2-receptor-stimulating sympathicomimetic agent (NAB 365) in horses with respiratory disease. Tijdschrift voor Diergeneeskunde 102: 1233-1238.

Savage, I.R., 1961. Probability inequalities of the Tchebycheff type. Journal of Research of the National Bureau of Standards - B. Mathematics and Mathematical Physics B 65: 211-222.

Sleeper, M.M., Kearns, C.F. and McKeever, K.H., 2002. Chronic clenbuterol administration negatively alters cardiac function. Medicine and Science in Sports and Exercise 34: 643-650.

Soma, L.R., Uboh, C.E., Guan, F., Moate, P., Luo, Y., Teleis, D., Li, R, Birks, E.K., Rudy, J.A. and Tsang, D.S., 2004. Pharmacokinetics and disposition of clenbuterol in the horse. Journal of Veterinary Pharmacology and Therapeutics 27: 71-77.

Thompson, J.A., Mirza, M.H., Barker, S.A., Morgan, T.W., Bauer, R.W. and McConnico, R.S., 2011. Clenbuterol toxicosis in three Quarter Horse racehorses after administration of a compounded product. Journal of the American Veterinary Medical Association 239: 842-849.

Turgut, K. and Sasse, H.H., 1989. Influence of clenbuterol on mucociliary transport in healthy horses and horses with chronic obstructive pulmonary disease. Veterinary Record 125: 526-530.

US Anti-Doping Agengy (USADA), 2019. Clenbuterol and meat contamination. Available at: https://tinyurl.com/yxlhgsxm

Wilsher, S., Allen, W.R. and Wood, J.L.N., 2006. Factors associated with failure of Thoroughbred horses to train and race. Equine Veterinary Journal 38: 113-118.

Wood, J.L.N., Newton, J.R., Chanter, N. and Mumford, J.A., 2005. Association between respiratory disease and bacterial and viral infections in British racehorses. Journal of Clinical Microbiology 43: 120-126. 